glucose uptake (IMGU) in NIDDM subjects: the role of blood flow. Diabetes 1991;40(suppl 1):100A.

27 Ferrari P, Weidmann P, Shaw S, Giachino D, Riesen W, Allemann Y, et al Altered insulin sensitivity, hyperinsulinemia and dyslipidemia in individuals with a hypertensive parent. $A m$ f Med 1991;91:589-96.

28 Randle PJ, Garland PB, Hales CN, Newsholme EA. The glucose fatty acid cycle: its role in insulin sensitivity and the metabolic disturbances of diabetes mellitus. Lancet 1963:i:785-9.

29 Moore RD. Effects of insulin upon ion transport. Biochim Biophys Acta 1983;737:1-49.

30 Julius S, Gudbrandsson T, Jamerson K, Shahab ST, Andersson O. The haemodynamic link between insulin resistance and hypertension. 7 Hypertens 1991;9:983-6.

31 Williams RR, Hunt SC, Hasstedt SJ, Hopkins PN, Wu LW, Berry TD, et al. Current knowledge regarding the genetics of human hypertension. f Hypertens 1989;7(suppl 6):8-13.

32 Bogardus C, Lillioja S, Howard BV, Reaven G, Mott D. Relationships between insulin secretion, insulin action and fasting plasma glucose concentration in nondiabetic and non-insulin-dependent diabetic subjects. fClin Invest 1984; $74: 1238-46$.

33 Reaven G, Miller R. Study of the relationship between glucose and insulin responses to an oral glucose load in man. Diabetes 1968;17:560-9,

34 Bogardus C, Lillioja S, Nyomba BL, Zurlo F, Swinburn B, Esposito-Del Puente $A$, et al. Distribution of in vivo insulin action in Pima Indians as mixture of three normal distributions. Diabetes 1989;38:1423-32.
35 Lillioja S, Mott DM, Zawadzki JK, Young AA, Abbott WGH, Knowler WC, et al. In vivo insulin action is familial characteristic in nondiabetic Pima Indians. Diabetes 1987;36:1329-35.

36 Raben N, Barbetti F, Cama A, Lesniak MA, Lillioja S, Zimmet P, et al. Normal coding sequence of insulin gene in Pima Indians and Nauruans, two groups with highest prevalence of type II diabetes. Diabetes 1991;40: $118-22$.

37 Oelbaum RS, Bouloux PM, Li SR, Baroni MG, Stocks J, Galton DJ. Insulin receptor gene polymorphisms in type 2 (non-insulin-dependent) diabetes mellitus. Diabetologia 1991;34:260-4.

38 Kusari J, Berma US, Buse JB, Henry RR, Olefsky JM. Analysis of the gene sequences of the insulin receptor and the insulin sensitive glucose transporter (GLUT-4) in patients with common type non-insulin-dependen diabetes mellitus. $\mathcal{F}$ Clin Invest 1991;88:1323-30.

39 Williams RR, Hunt SC, Hopkins PN, Stults BM, Wu L, Hasstedt S, et al. Familial dyslipidemic hypertension: evidence from 58 Utah families for syndrome present in approximately $12 \%$ of patients with essential hypertension. FAMA 1988;259:3579-86.

40 Reaven GM. Role of insulin resistance in human disease. Diabetes 1988;37: 1595-607.

41 Jarrett RJ. In defence of insulin: a critique of syndrome X. Lancet 1992;340: 469-7

(Accepted 11 May 1993)

\title{
A decade of diabetes: keeping children out of hospital
}

\author{
P G F Swift, J R Hearnshaw, J L Botha, G Wright, N T Raymond, K F Jamieson
}

\begin{abstract}
Objectives-To document the number of children aged less than 15 years who developed diabetes and were managed within one large health district, and to evaluate the outcome of those children managed without hospital admission at diagnosis.

Design-A retrospective study over 1979-88, when a paediatrician and a physician with special interests in childhood diabetes initiated joint clinics. Data collected from the district diabetes register and files of consultants and health visitors specialising in diabetes.
\end{abstract}

Setting-Referral of children to consultants in Leicestershire (total population 863000 ).

Main outcome measures-The proportion of children managed without hospital admission, comparison of readmission rates and glycated haemoglobin concentrations between children admitted and those not admitted.

Results-Over 10 years 236 children aged 10-14 years developed diabetes (annual incidence rate $12 \cdot 8 / 100000$ child population $(95 \%$ confidence interval $11 \cdot 3$ to $14 \cdot 7)$ ). In total 138 were not admitted to hospital but received supervised management based at home. Admitted children were younger or acidotic or their family doctors did not contact the diabetes team. Duration of admission declined from seven days in 1979-80 to three days in 1987-8. Ninety two were not admitted to hospital during the 10 years for any reason. Significantly fewer children who received management at home were readmitted for reasons related to diabetes than the group treated in hospital $(30(22 \%) v 40(41 \%) ; p=0 \cdot 004)$. Concentrations of glycated haemoglobin were no different between the two groups.

Conclusions-Children with newly diagnosed diabetes may be safely and effectively managed out of hospital. Domiciliary or community based management depends on the commitment of consultants specialising in diabetes working in close cooperation with general practitioners, specialist nurses in diabetes, and dietitians.

\section{Introduction}

The United Kingdom has a comprehensive primary and community health care system, including the widespread availability of specialist nurses in diabetes in at least $81 \%$ of health districts. ${ }^{1}$ Yet children with newly diagnosed diabetes are still routinely admitted to hospital. ${ }^{2}$ The British Paediatric Association's working party on children's diabetes services found that $87 \%$ of paediatricians reported that virtually all children were admitted at the time of diagnosis. ${ }^{1}$ In 1988, 1600 children under 15 years of age living in the British Isles developed diabetes. ${ }^{3}$ A subsequent survey of these children confirmed that $95 \%$ were admitted to hospital, $42 \%$ for more than seven days. ${ }^{4}$ In the United States a position statement in 1990 by the American Diabetes Association accepted that inpatient care was most appropriate for children and adolescents when diabetes was diagnosed.

Supervised outpatient management of children was described over 40 years ago in the United Kingdom ${ }^{26}$ and since the $1970 \mathrm{~s}$ in Israel ${ }^{7}$ and the United States. There is no published work showing that hospital admission for children who do not require intravenous treatment is necessary or beneficial. Indeed several studies assume that there are benefits from a shorter duration of admission if the initiation of insulin treatment and basic education can be accomplished by an organised specialist team, ${ }^{1011}$ particularly when specialist nurses in diabetes are available. ${ }^{11} 12$

The present study spanning the decade 1979-88 documents the number of children developing diabetes who were managed within a large NHS district (total population 863000); describes the management at diagnosis, drawing particular attention to the proportion of children not admitted to hospital; and evaluates the short and medium term efficacy of inpatient and outpatient management.

\section{Subjects and methods}

Names were identified of children aged 0-14 years who had developed insulin dependent diabetes between 1 January 1979 and 31 December 1988 from the Leicestershire diabetes register of all diabetic patients who were taking insulin (95-100\% complete for childhood diabetes ${ }^{13}$ ) and from consultants' card indexes. Data retrieved from the hospital notes of the children included date of diagnosis, age, duration of admission, where and by whom initially managed, readmissions to hospital, and reasons for readmissions. Analysis was made of all glycated haemoglobin concentrations during the 10 years of study. Compari- 
sons were made by using $\chi^{2}$ tests of independence, Student's $t$ tests, or Kruskal-Wallis tests. ${ }^{14}$

\section{Results}

A total of 236 children aged $0-14$ years at diagnosis who had developed diabetes in the 10 years after 1 January 1979 were identified. The annual incidence ranged from nine to 36 cases a year. The childhood population (0-14 years) in 1983 was 185000 , giving an average annual incidence of 12.8 cases $/ 100000$ ( $95 \%$ confidence interval $11 \cdot 3$ to $14 \cdot 7$ ).

\section{INITIAL MANAGEMENT}

At diagnosis 98 (42\%) children were admitted to hospital. Fifty three of these were admitted under the care of consultants who were not specialists in diabetes. Most of these children were transferred to the care of the paediatrician (PGFS) soon after admission.

The table gives the age distribution at admission and whether the children received an intravenous infusion. The median duration of admission was five days, this figure decreasing from seven days in 1979-80 to three days in 1987-8 (Kruskal-Wallis $\chi_{4 \mathrm{df}}^{2}=24 \cdot 03$, $\mathrm{p}=0.0001$ ). Seventy two children admitted were discharged in less than eight days. Of 21 children aged less than 5 years, $14(67 \%)$ remained in hospital for more than five days compared with 32 out of $77(42 \%)$ children aged more than 5 years who were admitted $\left(\chi_{1 \mathrm{df}}^{2}=4 \cdot 18, \mathrm{p}=0 \cdot 041\right)$.

Age distribution and initial management of children with diabetes

\begin{tabular}{lccc}
\hline & & \multicolumn{2}{c}{ Initial management } \\
\cline { 3 - 4 } & $\begin{array}{c}\text { No } \\
\text { (cumulative } \\
\text { \%) of } \\
\text { children } \\
\text { identified }\end{array}$ & $\begin{array}{c}\text { No (\%) } \\
\text { of } \\
\text { Age (years) }\end{array}$ & $\begin{array}{c}\text { admissions } \\
\text { admissions } \\
\text { receiving } \\
\text { intravenous } \\
\text { infusion }\end{array}$ \\
\hline $0-1$ & $6(3)$ & $6(100)$ & $3(50)$ \\
$2-4$ & $34(17)$ & $15(44)$ & $8(53)$ \\
$5-9$ & $81(51)$ & $38(47)$ & $20(53)$ \\
$10-14$ & $115(100)$ & $39(34)$ & $28(72)$ \\
\hline Total & $236(100)$ & $98(42)$ & $59(60)$ \\
\hline
\end{tabular}

There were seven children whose initial admission was for more than 10 days: four of these were admitted under the care of a consultant with no special interest in diabetes; two had serious social problems; and one was admitted with severe ketoacidosis with neurological sequelae.

In total $138(58 \%)$ children were not admitted to hospital. Of these, 95 received their first injection of insulin at home, 28 received their first injection in a ward side room and later went home, and 17 were managed through the outpatient department. One consultant (JRH) saw 101 of the children not admitted to hospital and managed 91 on a domiciliary basis. The consultant paediatrician (PGFS) saw 28 of these 138 children and managed 21 in the hospital ward side room. Twenty two children who were seen by other consultant teams avoided hospital admission, significantly fewer than those seen by the diabetes specialists $\left(\chi_{2 \mathrm{df}}^{2}=104.32, \mathrm{p}<0.0001\right)$.

\section{READMISSION}

In the total cohort $71(30 \%)$ required subsequent admission to hospital for a problem related to diabetes (hypoglycaemia, ketoacidosis, or other conditions not usually requiring admission in non-diabetic children). During the 10 years of study 92 (39\%) did not require admission to hospital at diagnosis or thereafter. Of the 98 children admitted to hospital at diagnosis, 40 required readmission for a problem related to diabetes compared with $31(22 \%)$ of the group who had initially been managed out of hospital $\left(\chi^{2}{ }_{1 \mathrm{df}}=9 \cdot 176, p=0 \cdot 001\right)$.

\section{Strategy for out of hospital management of} children with diabetes

DAY 1

1 Prompt diagnosis

2 Immediate telephone referral to specialist team

3 Availability of consultant for consultation

4 Domiciliary/outpatient consultation:

(a) confirmation of diagnosis

(b) initiation of insulin treatment

(c) simple explanation of diabetes

(d) action plan for next 24 hours

DAY 2

Home visit by specialist nurse in diabetes and/or community nurse (for injection support)

\section{SUBSEQUENT DAYS}

Regular home, clinic, and telephone contacts by team members

\section{RECURRENT READMISSIONS}

Five children required more than three readmissions related to diabetes. One of these children had been initially treated at home. One child was readmitted because of cataracts and later gynaecological problems, and the four others were readmitted with recurrent ketoacidosis or hypoglycaemia associated with recognisable developmental, behavioural, or cultural problems.

\section{BIOCHEMICAL CONTROL}

The mean glycated haemoglobin concentration in 1988 for children who had had diabetes for over two years was $10 \cdot 1 \%$ (normal range $4 \cdot 0-8 \cdot 5 \%$ ) with no significant difference $(t=0.9002,111 \mathrm{df}, \mathrm{p}=0.37)$ between the group treated at home $(10.2 \%)$ and those treated in hospital $(10 \cdot 0 \%)$.

\section{Discussion}

This study confirms that most children with newly diagnosed diabetes may be managed safely without admission to hospital. The success of management out of hospital depends on two vital factors. Firstly, the availability and commitment of consultant specialists in diabetes to initiate management outside the environment of the hospital ward. This often entails out of hours domiciliary visits or the use of off ward facilities. Secondly, the use of specialist nursing skills; in Leicestershire this is the diabetes health visitors with help from district (or community) nurses. The nurses visit the child's home on the second and subsequent days to teach and supervise injections and practical aspects of good management. Outpatient or domiciliary dietary advice is also available soon after diagnosis. The box outlines the strategy.

Outpatient management of patients with diabetes has been a feature in Leicestershire since the inception of the NHS in 1948. The first health visitor specialising in diabetes was appointed in 1950 and shortly afterwards the management of children as outpatients was described. ${ }^{\circ}$ In a more complete description of the children's diabetes service, ${ }^{15} 136$ children were diagnosed between 1950 and 1966. Only 35 referred directly to the diabetic clinic were admitted and 71 were not subsequently readmitted. In a larger survey of nearly 800 children diagnosed after 1930 the cohort was divided into index children (474), who were referred directly to the diabetic services and non-index children (323), who were treated outside the service but later referred into it. ${ }^{16}$ 
In total 389 of the index group were managed initially outside hospital and 356 did not require subsequent readmission. An analysis of long term vascular complications showed that $47(10 \%)$ of the index group showed proliferative retinopathy compared with $74(23 \%)$ in the non-index group after a duration of up to 35 years. Proteinuria, end stage renal failure, high blood pressure, and suboptimal growth had also been documented in the non-index group of this cohort $^{17}$ but the overall prevalence of vascular complications has been low compared with reports from other centres.

The present study differs from previous reports because it covers a time when a consultant physician in diabetes (JRH), who has advocated home stabilisation since 1967, and a consultant paediatrician with a special interest in diabetes (PGFS) worked in a joint clinic to manage all children with diabetes in a large well defined health district. During this time not only have over half of the children avoided admission to hospital but the mean length of stay has decreased significantly. In retrospect many of the 98 children admitted to hospital were admitted unnecessarily because of failure to make the diagnosis (particularly in the very young), because of onset of ketoacidosis, or because the diabetes team was not informed of the diagnosis. Of those who received an intravenous infusion, 27 had a blood $\mathrm{pH}>7 \cdot 2$ and had not vomited. They could have been managed as outpatients. In the second half of this study significantly fewer children were admitted with ketoacidosis and indeed since 1988 the proportion of children managed out of hospital has been in excess of $80 \%$.

It is not entirely clear why children managed out of hospital have fewer readmissions. It might be that the two groups are from different social backgrounds or that $\beta$ cell failure is more severe in the group admitted (particularly those with ketoacidosis). The finding of no difference in the glycated haemoglobin concentrations between the groups (including those with ketoacidosis) suggests that the latter argument is unlikely and analysis of those admitted with ketoacidosis shows that the social background of those treated at home is no different from that of those admitted. It is more likely, as Galatzer et al have observed, ${ }^{8}$ that by initiating the process of management of diabetes out of hospital and allowing parents to adjust by practical activity to the crisis of diagnosis subsequent problems are managed more effectively. We are certain that many potential crises are averted by parents making telephone contact with specialist health visitors or consultants and thus avoiding admissions.

The advantage of home based management is that it is performed by a small team of experienced staff. This avoids the inevitable conflicts and confusions of hospital admission by allowing the parents and child to feel in control from the time of diagnosis. They witness the clinical and biochemical improvements over the first hours and days because "education begins immediately, when they (the parents) are most receptive and they appreciate seeing for themselves the changes that occur in this phase." 16

Many professionals caring for children express the view that parents require respite, relief, and even a time for grieving ${ }^{118}$ organised by the hospital to cope with the shock of diagnosis. This is totally at variance with our experience over the past 40 years with parents

\section{Clinical implications}

- Most children with newly diagnosed diabetes can be safely and effectively managed out of hospital by a small dedicated team

- In this study children who were not admitted to hospital had fewer subsequent admissions and equally satisfactory biochemical control

- Strategy is home and parent centred, not hospital dependent

- Advantages implied are reduced hospital bed usage, improved community care, and enhancement of family confidence and skills

who express great relief that admission is avoided and from the time of diagnosis are able to show their own skills.

This study confirms that children developing diabetes at any age may be safely and effectively managed out of hospital if a specialist team committed to community management is available. This conclusion applies to many childhood and adult disorders. Furthermore, long term follow up studies of children diagnosed in this district suggest that consistent initial and continuing care is associated with a lower prevalence of vascular complications. ${ }^{16} 17$

The results emphasise the importance of the recommendations of the British Paediatric ${ }^{1}$ and Diabetic ${ }^{19}$ Associations that it is a priority to provide adequate numbers of specialist diabetes consultants, nurses, and dietitians in every health district.

1 British Paediatric Working Party Report. The organisation of services fo children with diabetes in the United Kingdom. Diabetic Med 1990;7:457-64.

2 Anon. Where to treat newly diagnosed diabetes. Lancet 1991;337:648-9.

3 Metcalfe MA, Baum JD. Incidence of insulin dependent diabetes in children aged under 15 years in the British Isles during 1988. BM7 1991;302:443-7.

4 Lessing DN, Swift PGF, Metcalfe MA, Baum JD. Newly diagnosed diabetes: a study of parental satisfaction. Arch Dis Child 1992;67:1011-3.

5 American Diabetes Association. Position statement. Hospital admission guidelines for diabetes mellitus. Diabetes Care 1990;13:1118-9.

Walker JB. Field work of a diabetic clinic. Lancet 1953;ii:445-7.

7 Laron Z, Galatzer A, Amir S, Gil R, Karp M, Mimouni M. A multidisciplinary, comprehensive, ambulatory scheme for diabetes mellitus in children. Diabetes Care 1979;2:342-8.

8 Galatzer A, Amir S, Gil R, Karp M, Laron Z. Crisis intervention program in newly diagnosed diabetic children. Diabetes Care 1982;5:414-9.

9 Schneider AJ. Starting insulin therapy in children with newly diagnosed diabetes--an outpatient approach. Am f Dis Child 1983;137:782-6.

10 Simell T, Kaprio EA, Maenpaa J, Tuominen J, Simell O. Randomise prospective study of short-term and long-term stay in hospital by childre with diabetes mellitus. Lancet 1991;337:656-60.

11 Rayner PHW. A home care team for diabetic children. Practical Diabetes 1984;1:5-6.

12 Lipman TH. Length of hospitalisation of children with diabetes: effect of a clinical nurse specialist. The Diabetes Educator 1986;14:41-3.

13 Diabetes Epidemiology Research International Group. Secular trends in incidence of childhood IDDM in 10 countries. Diabetes 1990;39:858-64.

14 SAS Institute. SAS user's guide: basics. Version 5. Cary, North Carolina: SAS Institute, 1985 .

15 Walker JB. Chronicle of a diabetic service. London: British Diabetic Association Publications, 1989.

16 Hearnshaw JR. Childhood and after-a review of childhood diabetes in an English community 1930-1985. In: Serrano-Rios M, Lefebre PJ, eds. Diabetes 1985. Amsterdam: Elsevier, 1986:31-42.

17 McNally PG, Burden AC, Swift PGF, Walls J, Hearnshaw JR. The prevalence and risk factors associated with the onset of diabetic nephropathy in juvenile-onset (insulin dependent) diabetics diagnosed under the age of 17 years in Leicestershire 1930-1985. Qf Med 1990;76:831-44.

18 Lindsay M. Emotional management. In: Baum JD, Kinmouth A-L, eds. Car of the child with diabetes. Edinburgh: Churchill-Livingstone, 1985.

19 Medical Advisory Committee of the British Diabetic Association. Minimal educational facilities. London: British Diabetic Association, 1986.

(Accepted 11 May 1993) 